\title{
Tympanostomy Tube Placement and Vestibular Function in Children
}

\author{
Michael S. Cohen, MD ${ }^{1,2}$, Ellen M. Mandel, MD, MS ${ }^{1,2}$, Joseph M. Furman, MD², Patrick J. \\ Sparto, $\mathrm{PhD}, \mathrm{PT}^{3}$, and Margaretha L. Casselbrant, $\mathrm{MD}, \mathrm{PhD}^{1,2}$ \\ ${ }^{1}$ Division of Pediatric Otolaryngology, Children's Hospital of Pittsburgh of UPMC, Pittsburgh, PA \\ ${ }^{2}$ Department of Otolaryngology, University of Pittsburgh, Pittsburgh, PA \\ ${ }^{3}$ Department of Physical Therapy, University of Pittsburgh, Pittsburgh, PA
}

\section{Abstract}

Objective-To determine the effect of bilateral myringotomy with tube placement (BMT) on balance in children 4 to 7 years old

Study Design—Case-control study

Setting-Tertiary-care academic hospital

Subjects and Methods-Children with otitis media with effusion (OME) who were scheduled for BMT underwent rotational chair testing (RCT) and computerized dynamic posturography (CDP) preoperatively and at 1, 3, and 6 months postoperatively. Control children without a significant history of middle-ear disease were tested at the same intervals. Analysis of covariance was performed to evaluate the effect of BMT on RCT and CDP outcomes with age as a covariate.

Results-Seventy-two cases and fifty-six controls were enrolled. Mean age was 69 (SD 12) months for cases and 72 (SD 15) months for controls. No difference was seen between groups on RCT outcomes or sensory organization test (SOT) scores. Higher sway velocity during CDP was observed in the OME group both preoperatively and one month postoperatively. This difference was not statistically significant. There was no difference between groups three months postoperatively. At six months, the BMT group had a statistically-significant decrease in sway velocity compared to the control group.

Conclusion-No difference was observed between children with OME and controls in RCT or SOT scores. Gradual improvement in sway velocity was observed after BMT. At the final timepoint, the groups did significantly differ in speed of sway, though the preoperative baseline difference failed to reach statistical significance. We suggest that physicians continue to inquire about balance development in patients with OME.

\section{Introduction}

Otitis media with effusion (OME) is defined as the presence of a middle-ear effusion without signs or symptoms of acute infection, and it is one of the most common reasons for physicians' office visits in children. ${ }^{1}$ While conductive hearing loss and speech delay are the clinical findings most commonly associated with OME, there exists both anecdotal and experimental evidence that balance disturbances are a major consequence of this condition.

Corresponding Author: Michael S. Cohen, MD; Pediatric Otolaryngology, Children's Hospital of Pittsburgh of UPMC; 4401 Penn Avenue; Faculty Pavilion $7^{\text {th }}$ Floor; Pittsburgh, PA 15224 Tel: (412) 692-8577; Fax: (412) 692-6074 michael.cohen@ @ chp.edu. 
Furthermore, parents often comment that their child's first steps or other major physical developmental milestones shortly followed insertion of tympanostomy tubes.

OME is often cited as one of the most common causes of dizziness in children. ${ }^{2-7}$ The first studies seeking to quantify this relationship began in the 1980's. ${ }^{8}{ }^{8}$ While these studies did generally find associations between balance and vestibular dysfunction and middle ear effusion, the study populations were generally small or the means of quantification somewhat non-specific.

The literature to date is relatively sparse in assessing the effect of bilateral myringotomy with tube insertion (BMT) on balance in children with OME. In the 1990s, several authors studied this relationship. Golz and colleagues measured the VOR in 50 children with OME and found abnormal electronystagmography in $71 \%$ of children with OME compared with $4 \%$ of normal controls. These abnormal findings resolved after bilateral myringotomy with tube insertion. ${ }^{10}$ Casselbrant and colleagues used posturography to compare a group of 41 children from 3 to 14 years of age with OME to 50 children without middle ear disease and found a significantly higher mean velocity of sway in the OME group. Again, values were found to improve after BMT. ${ }^{11}$ Jones and colleagues (1990) measured sway velocity in 34 children with OME and found higher velocity in subjects with OME compared to normal controls. This difference resolved four months following myringotomy with tube insertion. ${ }^{12}$ Hart and colleagues (1998) compared 19 four- to six-year-old children with OME scheduled for tympanostomy tube insertion to 14 matched controls using the Peabody Developmental Motor Scales and the Bruininks-Oseretsky Test of Motor Proficiency, two validated testing instruments of motor and balance development. The OME group demonstrated significantly lower performance in the balance subscales prior to tube insertion. While the average improvement in the otitis group was greater than in the control group on repeat testing, the difference was not statistically significant. ${ }^{13}$

In a longitudinal study conducted by this group, rotational chair and posturography testing were conducted in children aged three to nine over a six year period to establish normative data for these modalities. A linear relationship between age and balance testing performance was identified. ${ }^{14}$

Using the studies described above as a guide, the present study was designed to prospectively assess the relationship between OME and balance function in children, controlling for age, in order to assess whether an effect exists and, if so, whether the effect is reversed by insertion of tympanostomy tubes.

\section{Methods}

\section{Population and Enrollment}

This study was conducted in collaboration between the Ear Nose and Throat Research Center (ENT-RC) at the Children's Hospital of Pittsburgh (CHP) and the Center for Balance Disorders at the Eye and Ear Institute of Pittsburgh. Children between 4 and 7 years of age with persistent middle-ear effusion who were scheduled to undergo BMT were recruited from the ENT clinic at CHP and from a synchronous longitudinal study at CHP whose aim was to establish normative data for posturography and rotational testing in children. ${ }^{14}$ Control subjects without middle-ear effusion and without a significant history of middle-ear disease, (defined as $<2$ episodes of otitis media as determined from review of their medical records) were recruited at CHP. Informed consent for each child to participate in this study was obtained. This study was approved by the CHP Human Rights Committee and the Institutional Review Board of the University of Pittsburgh. 
Potential subjects were excluded from the study if they met any of the following criteria: birth weight <2500 grams; history of neonatal asphyxia or other serious illness; major congenital malformation or other major abnormality; congenital malformation of the external, middle, or inner ear; sensorineural hearing loss; otoneurologic disease; history of ear surgery such as tympanoplasty, tympanomastoidectomy, mastoidectomy, cholesteatoma or chronic mastoiditis; intratemporal or intracranial suppurative complications of otitis media; use of ototoxic medication (except topical use); or unreliable historical information or inadequate comprehension or cooperation.

\section{Procedures}

Demographic data and medical history, including history of otitis media, gender, race, history of adenoidectomy, maternal education, daily home environment, and tobacco exposure were obtained at entry. An otoscopic examination, tympanometry and behavioral audiometry were performed on the same day as vestibular testing. Middle-ear effusion was diagnosed using a combination of pneumatic otoscopy by a validated otoscopist and immitance testing based on an algorithm previously described by this group. ${ }^{15}$ Immittance testing was obtained using a GSI-38 Middle Ear Analyzer (Grason-Stadler, Inc., Milford, $\mathrm{NH})$. For all cases enrolled in this study, complete audiologic and vestibular evaluation were performed one week prior to BMT, at which time all subjects had OME in at least one ear, with follow-up testing at one, three, and six months postoperatively. Control subjects were tested over the same time-frame, and were effusion-free bilaterally at the time of testing.

Vestibular function testing included assessment of the vestibulo-ocular and vestibulo-spinal reflexes by rotational testing using a rotary chair and dynamic platform posturography using the Equitest system, respectively. The testing methods used were identical to those described previously in the longitudinal study by this group. ${ }^{14}$ Additionally, the center of pressure (COP) data were extracted from the SOT conditions. Each component of the COP in the anterior-posterior and medial-lateral direction was differentiated to compute the sway velocity. A resultant sway velocity was then generated by computing the vector sum of the two components. Finally, the root-mean-square was recorded as the magnitude of the sway velocity.

\section{Statistical Methods}

Data generated by rotational testing included gain, phase, and symmetry of the VOR. The Sensory Organization Test (SOT, Neurocom, Inc) protocol yielded equilibrium scores and sway velocity scores were computed for 6 sensory conditions: eyes open, eyes closed, and visual sway-referencing on level and sway-referenced surfaces. ${ }^{16}$ Analysis of covariance was performed to evaluate whether BMT had an effect on each variable at each time point with age used as a covariate in all analyses. Although there was no statistically significant difference in age among groups, age was used as a covariate as posturography scores have been demonstrated to improve with increasing age. ${ }^{14}$

Each time point was considered separately in order to maximize the number the subjects that could be used in the analysis. Due to subjects not returning for all visits, a repeated measures ANOVA would have severely limited the sample sizes used and limited the generalizability of the findings. Using a Bonferroni adjustment for multiple individual comparisons, a more conservative alpha level was established at 0.01 .

\section{Results}

Seventy-two cases and fifty-six controls were enrolled over a five year period. The subjects in both groups were similar in age, averaging $69(\mathrm{SD}+/-12)$ months for cases and 72 (SD 
+/- 15) months for controls. There was no significant difference in gender among groups, with males representing $61 \%$ of cases vs. $52 \%$ of controls. The racial distribution among groups was similar, and a slightly higher percentage of cases were exposed to tobacco smoke in the home compared to controls. Again, this difference did not reach statistical significance. (Table 1)

Table 2 demonstrates the gain and phase values for the rotational chair testing at different frequencies. No difference was seen between groups in gain, phase, or symmetry of the VOR as measured by RCT, after controlling for age. Table 3 displays the equilibrium scores obtained from the SOT for all six conditions and the composite score. There were no significant differences detected between the groups after controlling for age.

Speed of sway for each condition of the sensory organization test was calculated, and while differences were observed between cases and controls pre-operatively and one month postoperatively, these differences did not reach statistical significance, with p-values ranging from 0.04 to 0.28 preoperatively and from 0.06 to 0.19 at one month. There was no difference between groups observed at the three month post-operative visit $(\mathrm{p}=0.47$ to 0.89 ). At the 6 month time point, a difference was again seen between groups in all conditions of the SOT, with the BMT group demonstrating slower sway velocity than the control group. These differences were statistically significant, with p-values less than 0.007 for all conditions. (Figure and Table 4)

Sway velocity could not be calculated in instances where subjects fell. There was no statistically significant difference for number of falls between groups (Fisher's exact). No subjects fell at any time point in conditions 1-3. The number of falls per group for conditions 4-6 at each time point is summarized in Table 5 .

In response to the difference among groups in sway velocity at the 6 month time point, further analysis was performed to characterize those subjects tested at that time. First, we compared those cases who were tested at the six month time point with those who were not tested at the six month time point. There was no difference due to gender, age, race, or tobacco exposure among these groups, nor was there a difference among these groups in pre-BMT sway velocity. Second, we compared those cases and controls who were tested at the 6 month visit. Again, there was no difference due to gender, age, race, or tobacco exposure among these groups, nor was there a difference among these groups in pre-BMT sway velocity.

\section{Discussion}

Due to its high prevalence, even subtle sequelae of OME can have consequences for a large number of children. Parents often provide anecdotal evidence that their children with OME have disorganization of movement, delay in walking, and propensity for falls, especially compared to their peers without otitis media. Parents further report that their children often begin to walk or become less clumsy after BMT. Several studies have examined vestibular and balance function in children with OME, and yielded evidence suggesting a relationship among them.

Our study did not demonstrate a difference between groups preoperatively for rotational chair testing, a measure of the VOR. When comparing sway velocity, which assesses the vestibulospinal reflex and overall balance function, there appeared to be more of a difference among groups on pre-operative posturography testing. While the p-values for SOT conditions at this time-point were as low as 0.07 , they did not reach statistical significance. The data were similar at the one month time point, and no difference between 
groups was observed at three months. A statistically significant difference in favor of improved balance function was observed in the BMT group at the six month time-point.

No statistically significant difference between groups was observed for number of falls in each condition of the SOT. The absolute number of falls was greater in the BMT group than the control group. Fewer falls tended to occur in later trials for conditions 5 and 6 of the SOT. It is unclear whether incorporating speed of sway data (which was not technically feasible in this study) from these subjects would have caused a significant difference to be observed between groups for the earlier trials.

Strengths of this study include its prospective, case-control design and its setting in a dedicated balance laboratory with staff accustomed to working with children. Nonetheless, our data are somewhat limited by failure to achieve complete data sets for each subject. Testing fatigue in this patient population is common, and as a result missing or unobtained data points tended to cluster in the later iterations of the rotational chair testing and in all testing conducted at later study time points. Although theoretically such missing data could result in a selection bias, this was not specifically observed in our data.

In light of previous studies demonstrating an effect of OME on balance testing in children, and the proximity of the observed p-values at the preoperative time-point to the predetermined alpha for rejecting the null hypothesis in our study, it is tempting to conclude that the improvement in sway velocity over time in the OME group and the statistically significant difference between groups at the six month time-point reflect an effect of BMT on balance function. However, this interpretation must be made with real caution as there is not an obvious physiological explanation for why the BMT group should do better on balance testing that the controls at the six month time point. One theory, that children who were more likely to do poorly on testing were also more likely to drop out by the six month time-point, was not borne out by further analysis of the data as decribed in the results section above.

Strong anecdotal and clinical experimental evidence exists for the association between OME and balance dysfunction in children. ${ }^{2-14}$ While the difference between groups in our study did not reach statistical significance, we did observe a decrease in mean sway velocity over time after tympanostomy tube insertion in children with OME. Furthermore, children in the BMT group were observed to have higher variability in sway velocity than the control group; this variability decreased with incremental time points. This pattern suggests that OME may have interfered with balance function in some subjects in our study population.

We would suggest that our data support the recommendations of the clinical practice guidelines of the American Academy of Otolaryngology-Head and Neck surgery. ${ }^{17}$ Specifically, when making a clinical decision regarding tympanostomy tube insertion in children with OME, it is important for practitioners to elicit a history of balance problems, unexplained clumsiness, or delayed gross motor development.

\section{Conclusion}

In contrast to several previous studies examining balance dysfunction in children with OME, this prospective study was unable to resolve a statistically significant difference between children with OME and controls in rotational testing and SOT composite scores. By the end of our study, the groups did significantly differ in speed of sway, though the measured baseline difference failed to reach statistical significance. These trends between groups preoperatively as well as improvement in balance function over time in the OME group support the practice of considering balance development in addition to hearing and speech 
development when evaluating children with OME. Therefore we suggest that it remains important for physicians to inquire about balance symptoms and gross motor development in each patient with OME.

\section{Acknowledgments}

This study was supported by NIH grant 1RO1 DC2490-01A1 and GCRC grant M01-RR00084. We would like to acknowledge the contributions of our colleagues: Kathleen Tekely, RN, for help in recruiting and following subjects; Anita Lieb and Susan Strelinski for performing the testing; Mark Redfern, PhD, for assistance with data acquisition; and Marcia Kurs-Lasky, MS, for help in data management.

Supported by NIH grant 1RO1 DC2490-01A1 and GCRC grant M01-RR00084 Presented at the 2010 American Academy of Otolaryngology-Head and Neck Surgery Annual Meeting, Boston, MA (September 29, 2010).

\section{References}

1. Teele DW, Klein JO, Rosner B, et al. Burden and the practice of pediatrics: Middle ear disease during the first five years of life. JAMA. 1983; 249:1026. [PubMed: 6823056]

2. Mercia FS. Vertigo due to obstruction of the Eustachian tube. JAMA. 1942; 118:1282.

3. Busis SN. Vertigo in children. Pediatr Ann. 1976; 5(8):478-481. [PubMed: 958738]

4. Fried MP. The evaluation of vertigo in children. Laryngoscope. 1980; 90:548-1560.

5. Gates GA. Vertigo in children. Ear Nose Throat J. 1980; 59:44.

6. Blayney AW, Colman BH. Dizziness in childhood. Clin Otolaryngol. 1984; 9:77. [PubMed: 6540635]

7. Balkany TJ, Finkel RS. The dizzy child. Ear Hear. 1986; 7(3):138-142. [PubMed: 3721084]

8. Casselbrant ML, Black FO, Nashner L, et al. Vestibular function assessment in children with otitis media. Ann Otol Rhinol Laryngol. 1983; 107:46.

9. Schaaf RC. The frequency of vestibular disorders in developmentally delayed preschoolers with otitis media. Am J Occup Ther. 1985; 39(4):247-252. [PubMed: 2581452]

10. Golz A, Westerman ST, Gilbert LM, et al. Effect of middle ear effusion on the vestibular labyrinth. J Laryngol Otol. 1991; 105(12):987-989. [PubMed: 1787379]

11. Casselbrant ML, Furman JM, Rubenstein E, et al. Effect of otitis media on the vestibular system in children. Ann Otol Rhinol Laryngol. 1995; 104(8):620-624. [PubMed: 7639471]

12. Jones NS, Radomskij P, Prichard AJ, et al. Imbalance and chronic secretory otitis media in children: effect of myringotomy and insertion of ventilation tubes on body sway. Ann Otol Rhinol Laryngol. 1990; 99(6 Pt 1):477-481. [PubMed: 2350133]

13. Hart MC, Nichols DS, Butler EM, et al. Childhood imbalance and chronic otitis media with effusion: effect of tympanostomy tube insertion on standardized tests of balance and locomotion. Laryngoscope. 1998; 108(5):665-70. [PubMed: 9591543]

14. Casselbrant ML, Mandel EM, Sparto PJ, et al. Longitudinal posturography and rotational testing in children three to nine years of age: Normative data. Otolaryngol Head Neck Surg. 2010; 142:708714. [PubMed: 20416461]

15. Nozza, RJ.; Bluestone, CD.; Kardatzke, D. Sensitivity, specificity and predictive value of immittance measures in the identification of middle ear effusion.. In: Bess FH, H.J.e., editor. Screening Children for Auditory Function. Bill Wilkerson Center Press; Nashville: 1992. p. 315-329.

16. Nashner LM, Black FO, Wall C. Adaptation to altered support and visual conditions during stance: patients with vestibular deficits. J Neurosci. 1982; 5:117-124.

17. Rosenfeld RM, Culpepper L, Doyle KJ, et al. Clinical practice guideline: Otitis media with effusion. Otolaryngol Head Neck Surg. 2004; 130(5):S95-S118. [PubMed: 15138413] 
Speed of Sway Preop

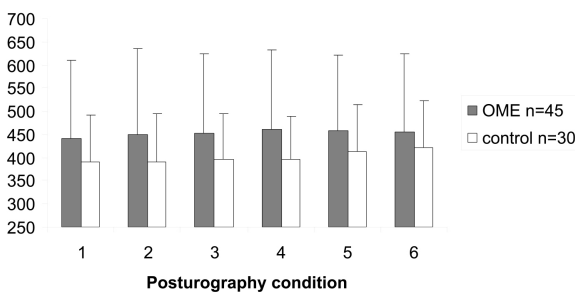

Speed of Sway 3 months Postop

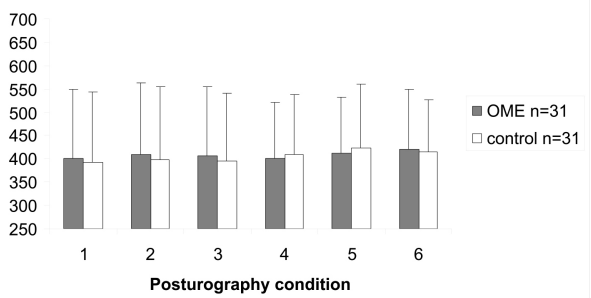

Speed of Sway 1 month Postop

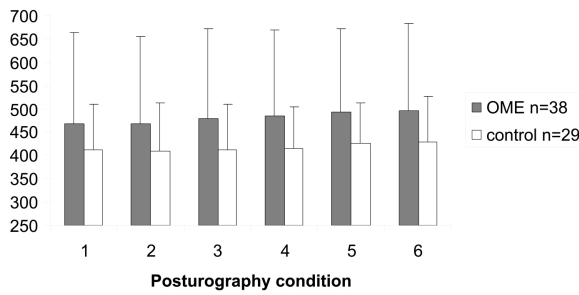

Speed of Sway 6 months Postop

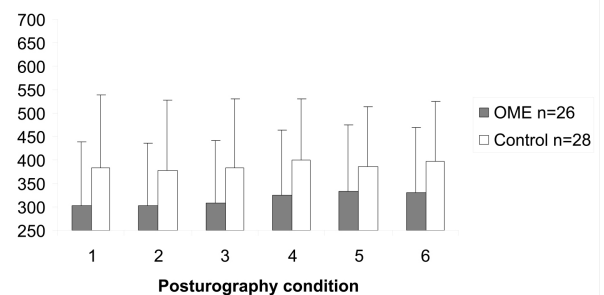

Figure 1.

Sway velocity scores for cases and control in each of the six conditions of the sensory organization test at each of the study time-points. Error bars reflect standard error. 
Table 1

\begin{tabular}{|l|c|c|c|c|c|}
\hline Demographics & Cases & & Controls & & \\
\hline & $\mathbf{N}$ & $\boldsymbol{\%}$ & $\mathbf{N}$ & $\%$ & p-value \\
\hline Age at enrollment (months) & 69 & - & 72 & - & 0.26 \\
\hline Gender & & & & & \\
\hline male & 44 & 61 & 29 & 52 & 0.29 \\
\hline female & 28 & 39 & 27 & 48 & \\
\hline Race & & & & & \\
\hline white & 57 & 79 & 40 & 71 & 0.31 \\
\hline black & 14 & 19 & 12 & 21 & \\
\hline multiracial & 1 & 2 & 1 & 2 & \\
\hline asian & 0 & 0 & 1 & 2 & \\
\hline other & 0 & 0 & 2 & 4 & \\
\hline Tobacco exposure & & & & & \\
\hline no & 48 & 67 & 42 & 75 & 0.31 \\
\hline yes & 24 & 33 & 14 & 25 & \\
\hline
\end{tabular}

Patient demographics by group. p-values obtained from t-test for Age, and $\chi^{2}$ test for Gender, Race, and Tobacco exposure. 
Table 2

\begin{tabular}{|c|c|c|c|c|c|}
\hline Time & Rotation & Condition & Cases (SD) & Controls (SD) & p-value \\
\hline Pre & & $\mathrm{N}$ & 54 & 38 & \\
\hline & $0.02 \mathrm{~Hz}$ & Gain & $0.54(0.14)$ & $0.53(0.17)$ & 0.94 \\
\hline & & Phase $\left(^{\circ}\right)$ & $26(8)$ & $25(8)$ & 0.56 \\
\hline & & $\mathrm{N}$ & 54 & 40 & \\
\hline & $0.05 \mathrm{~Hz}$ & Gain & $0.61(0.13)$ & $0.60(0.19)$ & 0.88 \\
\hline & & Phase $\left(^{\circ}\right)$ & $14(6)$ & $12(5)$ & 0.17 \\
\hline & & $\mathrm{N}$ & 26 & 34 & \\
\hline & $0.10 \mathrm{~Hz}$ & Gain & $0.59(0.12)$ & $0.62(0.20)$ & 0.47 \\
\hline & & Phase $\left(^{\circ}\right)$ & $8(5)$ & $8(5)$ & 0.97 \\
\hline & & $\mathrm{N}$ & 28 & 30 & \\
\hline & $0.50 \mathrm{~Hz}$ & Gain & $0.63(0.15)$ & $0.60(0.19)$ & 0.62 \\
\hline & & Phase $\left(^{\circ}\right)$ & $1(7)$ & $0(6)$ & 0.86 \\
\hline Post 1 month & & $\mathrm{N}$ & 41 & 30 & \\
\hline & $0.02 \mathrm{~Hz}$ & Gain & $0.55(0.16)$ & $0.52(0.15)$ & 0.63 \\
\hline & & Phase $\left(^{\circ}\right)$ & $26(11)$ & $27(8)$ & 0.80 \\
\hline & & $\mathrm{N}$ & 41 & 31 & \\
\hline & $0.05 \mathrm{~Hz}$ & Gain & $0.64(0.15)$ & $0.59(0.14)$ & 0.20 \\
\hline & & Phase $\left(^{\circ}\right)$ & $14(8)$ & $12(7)$ & 0.12 \\
\hline & & $\mathrm{N}$ & 20 & 28 & \\
\hline & $0.10 \mathrm{~Hz}$ & Gain & $0.62(0.17)$ & $0.62(0.16)$ & 0.68 \\
\hline & & Phase $\left(^{\circ}\right)$ & $8(5)$ & $10(9)$ & 0.36 \\
\hline & & $\mathrm{N}$ & 16 & 28 & \\
\hline & $0.50 \mathrm{~Hz}$ & Gain & $0.63(0.12)$ & $0.64(0.16)$ & 0.77 \\
\hline & & Phase $\left(^{\circ}\right)$ & $-1(5)$ & $1(6)$ & 0.38 \\
\hline Post 6 months & & $\mathrm{N}$ & 28 & 30 & \\
\hline & $0.02 \mathrm{~Hz}$ & Gain & $0.57(0.16)$ & $0.53(0.12)$ & 0.29 \\
\hline & & Phase $\left(^{\circ}\right)$ & $24(8)$ & $24(15)$ & 0.92 \\
\hline & & $\mathrm{N}$ & 28 & 32 & \\
\hline & $0.05 \mathrm{~Hz}$ & Gain & $0.64(0.12)$ & $0.63(0.13)$ & 0.82 \\
\hline & & Phase $\left({ }^{\circ}\right)$ & $15(6)$ & $14(5)$ & 0.63 \\
\hline & & $\mathrm{N}$ & 12 & 16 & \\
\hline & $0.10 \mathrm{~Hz}$ & Gain & $0.68(0.19)$ & $0.61(0.14)$ & 0.17 \\
\hline & & Phase $\left({ }^{\circ}\right)$ & $9(4)$ & $6(5)$ & 0.19 \\
\hline & & $\mathrm{N}$ & $\mathrm{n}=10$ & $\mathrm{n}=16$ & \\
\hline & $0.50 \mathrm{~Hz}$ & Gain & $0.70(0.16)$ & $0.67(0.20)$ & 0.64 \\
\hline & & Phase $\left({ }^{\circ}\right)$ & $1(5)$ & $1(7)$ & 0.62 \\
\hline
\end{tabular}

Rotational chair testing scores are given for gain and phase of the vestibulo-ocular reflex. Standard deviation in parentheses. 
Table 3

\begin{tabular}{|c|c|c|c|c|}
\hline Time & SOT Condition & Cases (SD) & Controls (SD) & p-value \\
\hline \multirow[t]{8}{*}{ Pre } & $\mathrm{N}$ & 60 & 46 & \\
\hline & Condition 1 & $83(6)$ & $85(6)$ & 0.15 \\
\hline & Condition 2 & $79(8)$ & $79(8)$ & 0.86 \\
\hline & Condition 3 & $77(9)$ & $78(13)$ & 0.75 \\
\hline & Condition 4 & $56(20)$ & $55(18)$ & 0.67 \\
\hline & Condition 5 & $39(17)$ & $39(15)$ & 0.85 \\
\hline & Condition 6 & $33(23)$ & $28(20)$ & 0.19 \\
\hline & Composite & $61(9)$ & $61(8)$ & 0.50 \\
\hline \multirow[t]{8}{*}{ Post 1 month } & $\mathrm{N}$ & 54 & 41 & \\
\hline & Condition 1 & $83(10)$ & $84(7)$ & 0.81 \\
\hline & Condition 2 & $77(8)$ & $79(8)$ & 0.42 \\
\hline & Condition 3 & $76(9)$ & $79(10)$ & 0.32 \\
\hline & Condition 4 & $57(20)$ & $58(15)$ & 0.84 \\
\hline & Condition 5 & $41(18)$ & $41(15)$ & 0.77 \\
\hline & Condition 6 & $39(20)$ & $34(19)$ & 0.22 \\
\hline & Composite & $62(10)$ & $63(8)$ & 0.74 \\
\hline \multirow[t]{8}{*}{ Post 3 months } & $\mathrm{N}$ & 42 & 39 & \\
\hline & Condition 1 & $84(7)$ & $85(6)$ & 0.67 \\
\hline & Condition 2 & $78(8)$ & $78(12)$ & 0.73 \\
\hline & Condition 3 & $78(11)$ & $78(12)$ & 0.93 \\
\hline & Condition 4 & $59(19)$ & $51(22)$ & 0.08 \\
\hline & Condition 5 & $46(16)$ & $39(16)$ & 0.07 \\
\hline & Condition 6 & $44(20)$ & $32(24)$ & 0.014 \\
\hline & Composite & $65(9)$ & $61(11)$ & 0.05 \\
\hline \multirow[t]{8}{*}{ Post 6 months } & $\mathrm{N}$ & 33 & 35 & \\
\hline & Condition 1 & $82(12)$ & $85(5)$ & 0.26 \\
\hline & Condition 2 & $78(11)$ & $79(10)$ & 0.74 \\
\hline & Condition 3 & $76(11)$ & $78(9)$ & 0.53 \\
\hline & Condition 4 & $57(22)$ & $57(14)$ & 0.85 \\
\hline & Condition 5 & $42(17)$ & $40(18)$ & 0.74 \\
\hline & Condition 6 & $40(20)$ & $32(20)$ & 0.11 \\
\hline & Composite & $63(12)$ & $62(8)$ & 0.92 \\
\hline
\end{tabular}

Posturography scores for each condition of the sensory organization test and composite score. Standard deviation in parentheses. p-values obtained from ANCOVA with age at time of testing as a covariate. SOT= sensory organization test 
Table 4

\begin{tabular}{|c|c|c|c|c|}
\hline Time & SOT Condition & Cases (SD) & Controls (SD) & p-value \\
\hline \multirow[t]{7}{*}{ Pre } & $\mathrm{N}$ & 43 & 31 & \\
\hline & Condition 1 & 441 (173) & $392(103)$ & 0.13 \\
\hline & Condition 2 & 452 (186) & 394 (104) & 0.08 \\
\hline & Condition 3 & 449 (172) & $398(100)$ & 0.11 \\
\hline & Condition 4 & 457 (177) & 398 (96) & 0.07 \\
\hline & Condition 5 & $456(164)$ & $413(102)$ & 0.25 \\
\hline & Condition 6 & 457 (173) & $422(102)$ & 0.26 \\
\hline \multirow[t]{7}{*}{ Post 1 month } & $\mathrm{N}$ & 38 & 28 & \\
\hline & Condition 1 & 469 (198) & $413(100)$ & 0.26 \\
\hline & Condition 2 & 468 (188) & 409 (104) & 0.20 \\
\hline & Condition 3 & 478 (196) & $414(101)$ & 0.18 \\
\hline & Condition 4 & 485 (187) & 415 (93) & 0.11 \\
\hline & Condition 5 & 494 (178) & 425 (89) & 0.07 \\
\hline & Condition 6 & 494 (190) & $430(99)$ & 0.19 \\
\hline \multirow[t]{7}{*}{ Post 3 months } & $\mathrm{N}$ & 29 & 32 & \\
\hline & Condition 1 & 390 (133) & $392(152)$ & 0.63 \\
\hline & Condition 2 & 398 (139) & 399 (156) & 0.66 \\
\hline & Condition 3 & 398 (138) & 397 (145) & 0.71 \\
\hline & Condition 4 & $402(123)$ & $410(30)$ & 0.46 \\
\hline & Condition 5 & 415 (120) & $424(135)$ & 0.52 \\
\hline & Condition 6 & $422(132)$ & 415 (111) & 0.88 \\
\hline \multirow[t]{7}{*}{ Post 6 months } & $\mathrm{N}$ & 26 & 28 & \\
\hline & Condition 1 & 302 (136) & $380(156)$ & 0.004 \\
\hline & Condition 2 & $302(135)$ & $373(150)$ & 0.004 \\
\hline & Condition 3 & 308 (133) & $380(148)$ & 0.005 \\
\hline & Condition 4 & $325(138)$ & 398 (133) & 0.002 \\
\hline & Condition 5 & 334 (142) & 387 (131) & 0.007 \\
\hline & Condition 6 & 330 (139) & 399 (129) & 0.003 \\
\hline
\end{tabular}

Sway velocity scores for each condition of the sensory organization test and composite score. Standard deviation in parentheses. p-values obtained from ANCOVA with age at time of testing as a covariate. SOT= sensory organization test 
Table 5

\begin{tabular}{|l|l|c|c|c|}
\hline \multicolumn{1}{|l|}{ Number of falls by group } & & \\
Time & SOT condition & Cases (\%) & Controls (\%) & p-value \\
Pre & N & 60 & 46 & \\
& Condition 4 & $2(3)$ & $1(2)$ & 1.0 \\
Post 1 month & Condition 5 & $4(7)$ & $2(4)$ & 0.70 \\
& Condition 6 & $14(23)$ & $12(26)$ & 0.82 \\
& N & 54 & 41 & \\
Post 3 months & Condition 4 & $3(6)$ & $0(0)$ & 0.26 \\
& Condition 5 & $3(6)$ & $0(0)$ & 0.26 \\
& Condition 6 & $7(13)$ & $5(12)$ & 1.0 \\
& Condition 4 & $1(2)$ & $3(8)$ & 0.35 \\
& Condition 5 & $1(2)$ & $1(3)$ & 1.0 \\
& Condition 6 & $3(7)$ & $9(23)$ & 0.06 \\
& N & 33 & 35 & \\
& Condition 4 & $3(9)$ & $0(0)$ & 0.11 \\
& Condition 5 & $1(3)$ & $1(3)$ & 1.0 \\
& Condition 6 & $3(9)$ & $5(14)$ & 0.71 \\
\hline
\end{tabular}

Number of falls for conditions 4 through 6 of the sensory organization test at each time point by group. p-values obtained from Fisher's exact test. SOT $=$ sensory organization test 